\title{
Multivariate Analysis Evaluation of Technological Process on Chemical and Sensory Acceptance of Yam and Soy Based Weaning Foods
}

\author{
Soronikpoho $\mathrm{S}^{1 *}$, Elleingand $\mathrm{EF}^{2}$, Fatoumata $\mathrm{C}^{3}$ and Ernest $\mathrm{K}^{1}$ \\ ${ }^{1}$ Laboratoire De Biochimie Et Sciences Des Aliments, UFR Biosciences, Université \\ Félix Houphouët-Boigny, Ivory Coast
}

2LAPISEN, Département de Génie Chimique et Agroalimentaire (GCAA) de L'Institut National Polytechnique Félix Houphouët Boigny (INP-HB), Ivory Coast

${ }^{3}$ Laboratoire de Nutrition et Sécurité Alimentaire, UFR Science et Technology des Aliments (STA), Université Nangui Abrogoua, Ivory Coast

*Corresponding author: Soro Soronikpoho, Laboratoire De Biochimie Et Sciences Des Aliments, UFR Biosciences, Université Félix Houphouët-Boigny, De Cocody, (UFHB) 22 Bp 582 Abidjan 22, Republique de cote d'ivoire, E-mail: soronik@yahoo.com

\section{Abstract}

Given the importance of yam worldwide in western Africa, and considering the absence of any scientific study setting out yam based weaning food sensory acceptance, it becomes important to identify the differentiating characteristics of several formulated brands. In particular, setting out the correlation between chemical, physical and sensory parameters. In this way, the aim of this work was to make yam (Dioscorea spp) more useful as low-cost and nutritive weaning food. It has been developed a scheme for processing it into infant flours with a long shelf-life. An attempt was allow highlighting how the incorporation of soybean (Glycine max) and natural sources of micronutrients (Andasonia digitata pulp, Parkia biglobosa pulp or seed, Cerathoteca sesamoides leaves) modifies sensory properties of formulated composite infant foods prepared. The elemental chemical analysis, determination of physical parameters and sensory evaluation of studied formulation were performed. Sensory properties of gruels were evaluated by the balance method in comparison with other commercial weaning food. Multivariate statistical methods (Pearson correlation and cluster analysis) were applied to estimating relationships in analysed data.

The results showed that the weaning food sensory acceptance is strongly related to variables associated fluidity, sweetness, aroma, mouth feel and some physicochemical properties like acidity and Water-holding capacity (WHC). 


\section{Food Science and Nutrition Technology}

Formulated complementary foods containing malted millet, MCS and MNB had good acceptability comparable to the references used.

Keywords: Process; Yam; Soy; Infant; Foods

Abbreviations: Water-Holding Capacity (WHC); CA: Cluster Analysis

\section{Introduction}

Yam (Dioscorea spp) is a local and readily available crop, in most part of western Africa [1]. It is a readily energy-rich, available and quite affordable product with promising economic value [2]. Yam may receive a lot of attention to formulated and developing nutritious weaning foods to fat malnutrition in developing countries [3]. Stimulating interest of used household traditional process and legumes notably soybean fortification, can help to attempt purpose of provided nutritious complementary foods based on this important root crop. But the nutritive utilization of legumes can be negatively affected by their content of ant nutritional factors such as phytic acid, which interfere with the digestive utilization of protein and minerals [4]. The use of yams as weaning food with securing desired functional properties could be increased by developing suitable processing technologies. This different process assayed, decreased phytate content and increased the bioavailability of protein and minerals [5]. It is evident that these appropriate processing methods used to eliminate or reduce ant nutrients concentration in legumes, leaves and pulp fruit had effect on sensory acceptance of gruels. Processing methods and fortification could affect the rheologies properties of gruels. Nevertheless, locally available weaning food commodities are not been carried out by a number of researchers. Despite the reported improvement in nutrient status of fermented cereal, root tubers, the acceptance and theologies properties of gruel of infant and sick adults are still not met.

In Ivory Coast biodiversity, pulp and leaft plant, providing highly nutritional concentrated sources such as Andasonia digitata, Parkia biblobosa and C. sesamoides with innumerable functional properties can be found. However, great part of those sources in formulated weaning food is still unknown.

The aim of this study was to use simple bioprocessing method which improved nutritional and sensory acceptance of yam-based infant flours. This research would provide an affordable and nutritious yam-based weaning food in order to reduce the incidence of malnutrition.

\section{Material and Methods}

\section{Material}

1. Material used in composite flours were yams (Dioscorea alata and Dioscorea cayenensis), soybean (Glycine max), malted millet grains, dried baobab pulp (Adansonia digitata), processed seeds and dried Nere pulp (Parkia biglobosa), processed and powdered Cerathoteca sesamoides leaves (Table 1).

2. Two types of industrial infant flours wellknown and saled in Côte d'Ivoire, Cerelac (infant cereal milk, NESTLE®) and FARINOR® (infant cereal milk, PKL) was taken as references.

\begin{tabular}{|c|c|c|c|c|c|c|c|c|c|c|c|c|}
\hline & $\begin{array}{c}\text { Vitamin } \\
\text { C }\end{array}$ & Acidity & WHC & Solubility & Gruel & Astringency & Fermented & Smoothly & Fluidity & $\begin{array}{c}\text { Sweet } \\
\text { ness }\end{array}$ & $\begin{array}{c}\text { Aroma } \\
\text { Mouth } \\
\text { feel }\end{array}$ \\
\hline Fluidity & 0,16 & $-0,51$ & $-0,61$ & 0,32 & 0,72 & $-0,70$ & $-0,69$ & 0,77 & 1 & & & \\
\hline Sweetness & 0,57 & $-0,76$ & $-0,58$ & 0,60 & 0,76 & $-0,78$ & $-0,83$ & 0,54 & 0,63 & 1 & & \\
\hline Aroma & 0,74 & $-0,74$ & $-0,74$ & 0,73 & 0,74 & $-0,89$ & $-0,89$ & 0,35 & 0,67 & 0,77 & 1 & \\
\hline Mouth feel & 0,56 & $-0,7$ & $-0,77$ & 0,61 & 0,78 & $-0,87$ & $-0,84$ & 0,52 & 0,86 & 0,75 & 0,92 & 1 \\
\hline Acceptability & 0,55 & $-0,70$ & $-0,76$ & 0,60 & 0,81 & $-0,89$ & $-0,82$ & 0,51 & 0,85 & 0,780 & 0,91 & 0,98 \\
\hline
\end{tabular}

1Significant correlation at $\mathrm{p}<0.05$.

Table 1: correlations between some physicochemical and sensory properties of samples of yam-based weaning flours 


\section{Food Science and Nutrition Technology}

\section{Material collection and preparation}

Sampling: Each material has been collected from local market where it is most common, in harvesting period. Yams, Dioscorea cayenensis variety kponan were purchased in November 2011. Dioscorea alata variety Bete Bete was purchased in January 2012. Soybeans were purchase in January 2012 from Bouake CNRA Station (Côte d'Ivoire). Baobab pulp (Adansonia digitata), seeds and Nere pulp (Parkia biglobosa) were purchased in Mars 2012. Cerathoteca sesamoides leaves were collected at maturity in fields in October 2011.

Samples preparation: Yams tubers, soybeans and C. sesamoides leaves were disinfected in diluted hypochlorite solution. The cleaned dry materials were then given different treatments. (Figure 1); outline the processing scheme of each material.
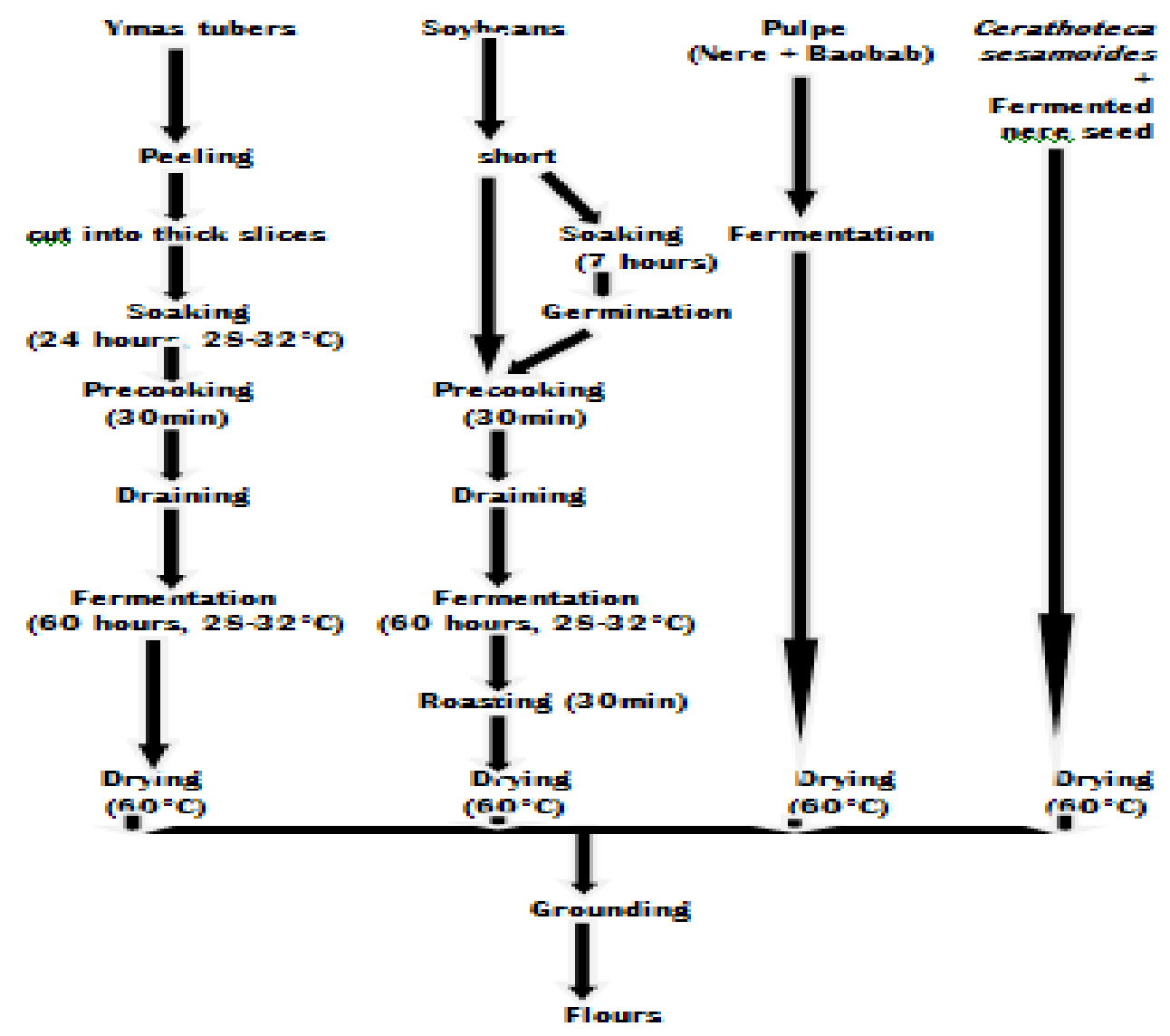

Figure 1: Flow diagram showing the yam-based weaning flours production process.

Preparation of malted millet: Millet grains were sorted, disinfected with diluted sodium hypochlorite solution [(8 $\left.{ }^{\circ} \mathrm{Chl}\right) 50 \mathrm{~mL} / 30 \mathrm{~L}$ water (v / v)] for $15 \mathrm{~min}$ and thoroughly rinsed with tap water. They were then soaked in water (15 L of water to $6 \mathrm{~kg}$ of seeds) for 7 hours. The seeds are then drained and made sprouted in a perforated container and covered to prevent direct sunlight. Germination took place in a room at $30 \pm 2{ }^{\circ} \mathrm{C}$ for $72 \mathrm{~h}$ and was followed by drying for 48 hours at $40 \pm 5{ }^{\circ} \mathrm{C}$. Malt thus obtained was desprouted, grilled, then drying and packaging.

Treatments of vegetables Cerathoteca sesamoides leaves: The shoots of Cerathoteca sesamoides were collected in the field and disinfected with diluted sodium hypochlorite solution for $15 \mathrm{~min}$ and thoroughly rinsed with tap water. Shoots have been suspended from a ribbon in the sun for 2 hours at $40^{\circ} \mathrm{C} \pm 5^{\circ} \mathrm{C}$. The shoots were then immersed in boiling water for 15 minutes, drained and put on sun. Leaflets were parts of shoots and then were sundried for 48 hours at $40 \pm 5{ }^{\circ} \mathrm{C}$.

Formulated infant flours and their abbreviations: The yam-based formulas were prepared by mixing (by weight), yam chips (55 or 60 or $70 \%$ ) with sprouted or unsprouted soybean (30\%), millet malt (10\%), pulp mixture (baobab+Nere) $(5 \%)$ or leaves powder (Nere 


\section{Food Science and Nutrition Technology}

seed+Cerathoteca sesamoides) (5\%). The mixture were milled using an electric grinder (Forplex model), pass through a $167-$ mesh $(0.25 \mathrm{~mm})$ sieve, packaged in airtight plastic containers and stored in a room at less than $25^{\circ} \mathrm{C}$. The different formulated flours were coded as follows:

BbSG $\quad: 70 \%$ fermented Bete Bete yam, and 30\% sprouted soybeans;

BbSNG : 70\% fermented Bete Bete yam (70\%), and $30 \%$ no sprouted soybeans;

BbSGM : $60 \%$ fermented Bete Bete yam (60\%), 30\% sprouted soybeans, and $10 \%$ millet malt;

BbSNGM : $60 \%$ fermented Bete Bete yam, 30\% no sprouted soybeans, and $10 \%$ millet malt;

BbSGMCS : 55\% fermented Bete Bete yam, 30\% sprouted soybeans, $10 \%$ millet malt, and $5 \%$ C. sesamoides;

BbSNGMCS : 55\% fermented Bete Bete yam, 30\% no sprouted soybeans, $10 \%$ millet malt, and

\section{$5 \%$ C. sesamoides;}

BbSGMNB : $55 \%$ fermented Bete Bete yam, 30\% sprouted soybeans (30\%), 10\% millet malt, and 5\% (Nere And baobab) ;

BbSNGMNB : $\quad 55 \%$ Bete Bete yam (55\%), 30\% no sprouted soybeans, $10 \%$ millet malt, and $5 \%$ (Nere and Baobab) ;

KpSG $\quad: \quad 70 \%$ fermented Kponan yam (70\%), and $30 \%$ sprouted soybeans;

KpSNG : $70 \%$ fermented Kponan yam $(70 \%)+$ no sprouted soybeans (30\%);;

KpSGM : $60 \%$ fermented Kponan yam (60\%), 30\% sprouted soybeans (30\%), 10\% millet malt;

KpSNGM : $60 \%$ fermented Kponan yam, 30\% no sprouted soybeans (30\%), and 10\% millet malt;

KpSGMCS : 55\% fermented Kponan yam, 30\% sprouted soybeans, $10 \%$ millet malt, and $5 \%$ C. sesamoides;

KpSNGMCS : $\quad 55 \%$ fermented kponan yam, 30\% no sprouted soybeans, $10 \%$ millet malt, $5 \% \mathrm{C}$. sesamoides ;

KpSGMNB : $55 \%$ fermented Kponan yam, 30\% sprouted soybeans, $10 \%$ millet malt, and $5 \%$ (Nere and

Baobab) ;

KpSNGMNB : $\quad 55 \%$ fermented kponan yam, 30\% no sprouted soybeans, $10 \%$ millet malt, and $5 \%$ (Nere and Baobab) ;

E17

Reference 1

E18 : Child Feeding Flour (cereal-milk):

Reference 2

Chemical analysis: For each sample, $\mathrm{pH}$, water-holding capacity (WHC), solubility index and acidity were de $\neg$ termined after two individual analyses. Samples and standard solutions were prepared according approved methods.
PH and titrable acidity: The $\mathrm{pH}$ of the flour was measured using a Inlab 421 Electrode attached with Delta 320 pH meter (Mettler-Toledo, AG 2007). Flour dispersion $(10 \%(\mathrm{w} / \mathrm{v}))$ was stirred for $30 \mathrm{~min}$, centrifuged at $3000 \times \mathrm{g}$ for $30 \mathrm{~min}$, and the $\mathrm{pH}$ of filtrate was measured [6]. Acidity of the same flour slurries were determined by titration with $\mathrm{NaOH}$ solution $0,1 \mathrm{~N}$ and phénolpthaléin 0, $1 \mathrm{~mol}$ / L.

Water-holding capacity (WHC) and solubility index: Distilled water, $15 \mathrm{~mL}$ were added to $0,3 \mathrm{~g}$ of flour, stirred and heated from 50 to $95^{\circ} \mathrm{C}$ in a water bath. The mixture was kept at $95^{\circ} \mathrm{C}$ for $15 \mathrm{~min}$ and was stirred constantly and cooled at room temperature. Tubes were centrifuged at $3000 \mathrm{xg}$ for $30 \mathrm{~min}$; the supernatant was decanted, dry at $105^{\circ} \mathrm{C}$ in a oven-drier. The dry solide obtained was weighed and solubility index was calculated as g solid per g flour. The residue in tubes was allowed to drain for 10 $\min$ at a $45^{\circ}$ angle. The residue was weighed and WHC calculated as g water per g dry sample $[7,8]$.

\section{Sensory evaluation}

Sample preparation: Then fifty gram (50 g) of sample flour was stirred gently into $150 \mathrm{~mL}$ of tap water. The porridge was stirred continuously about 8 min over low heat, had a dough-like consistency. $20 \mathrm{~g}$ or $10 \%$ sugar were added had the end of cooking. The slurries were allowed to cool to $50{ }^{\circ} \mathrm{C}$ before being served. In order to obtain the quantity of cooked paste needed for sensory test, $500 \mathrm{~g}$ of all samples were prepared.

Experimental design of descriptive quantitative analysis: Evaluation was done in a well lit sensory laboratory. The sensory profile of gruels included the following properties (taste, appearance, texture and color) of ready-to-eat formulated complementary foods was carried out by a 15 trained panelists (I2T employees) [9,10]. A continuous, one (minimum) to nine (maximum), scale was used to estimate the intensity sensed for each property. Before the evaluation, the samples were stabilized for $1 \mathrm{~h}$ at $45 \pm 1^{\circ} \mathrm{C}$. The samples were identified with three numbers chosen at random, and the code was different for each test [11].

Experimental design of hedonic scale preference test: This is a test which measures the subjective consumer acceptance and preference for products. This type of test consists in giving the samples to the assessors, questioning them about their preference between the different samples, according to an established scale. In hedonic scale, the assessor expresses its acceptance for the product, following a previously established scale that varies gradually, based on the attributes expressing its 


\section{Food Science and Nutrition Technology}

intensity. The scale points are distinguished verbally, so that they were associated with numerical values allowing statistical analysis [12]. The sensory panel was composed of a total of 42 participants. Regarding gender, $68 \%$ were male and $32 \%$ were female. The panel members carried out their evaluation by filling a questionnaire regarding the following attributes: visual, mouth feel, aroma, overall assessment. The assessors expressed the intensity of each attribute using a scale where 1 denotes a minimal value and 09 maximal [11].

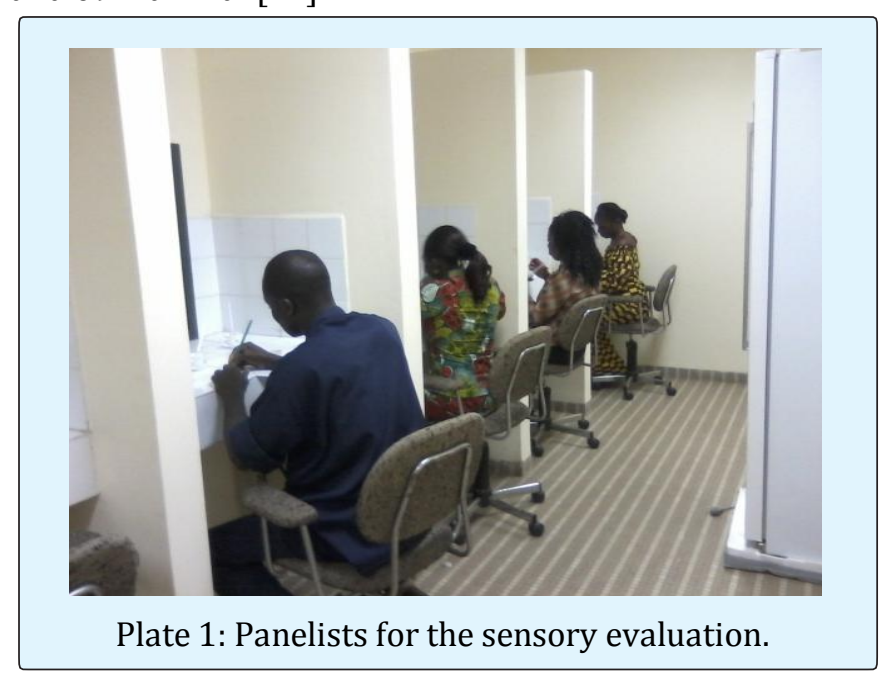

Multivariate statistical methods: Cluster analysis (CA) is a multivariate technique resulting of a hierarchical clustering procedure, displayed graphically using a tree diagram, and also known as a dendrogram. This dendogram shows all the steps in the hierarchical procedure [13,14]. The results were subjected to a Pearson correlation and Cluster Analysis (CA) in order to observe the differences and similarities of the samples analysed. The calculation of the Pearson correlation coefficients ( $r$ ) to determine the relationships between the various properties evaluated were done [15]. An analysis of correlation and a cluster analysis were performed. An analysis of variance, ANOVA and comparison of means differences for all parameters were done by Turkey HSD test, using the Statistical 8.0. The significance level used for all statistical tests was P $5 \%$.

\section{Results and Discussion}

Cluster analysis (CA), was used to identify the similarity groups between the sensory profile included the following properties (texture and color), hedonic following attributes (visual, mouth feel, aroma, overall assessment) of ready-to-eat market weaning flours gruels. This CA rendered a dendrogram showing in (Figure 2), grouping all sensory attributes into three statistically significant clusters (Cluster 1, cluster 2 and cluster 3 ).

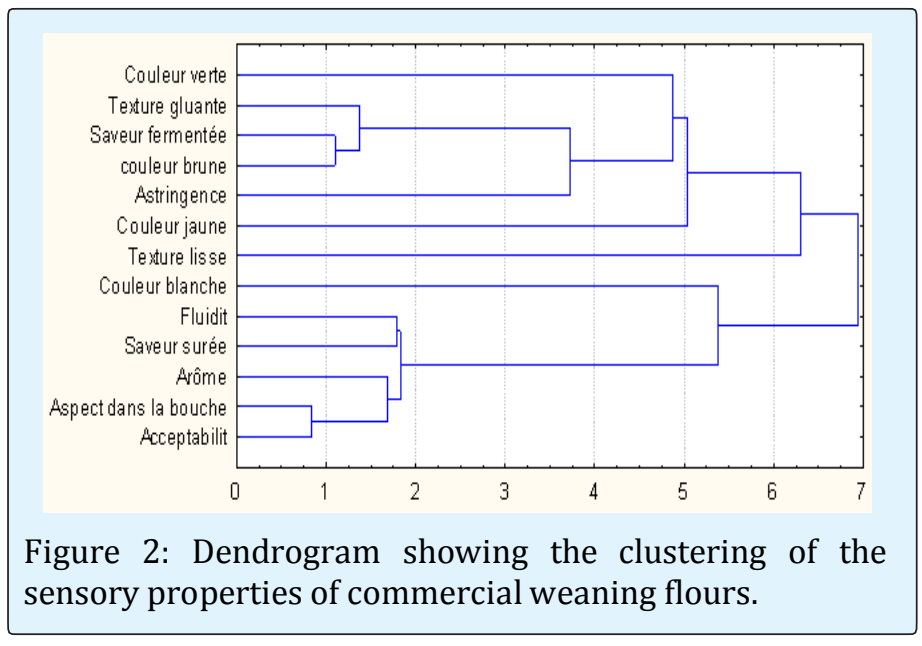

Clusters indicate that sensory properties of commercial weaning flour show greater fluctuation. This grouping gives evidence that samples in each group share each other and how they are sensed by the consumer. Result indicate that sensory attribute en cluster 1 (fluidity, sweetness, aroma, mouth feel, overall acceptability) were closely. Perhaps, the intensity of sensory attribute en cluster 3 (slimness, fermented and astringency) was slight, and was not clearly perceived by the sensory panel used. So these sensory attributes were found very different depending on the sample. However, sensory color assessment (in cluster 3) was problematic. The colours are related with many factors, revealed that the intensity of colour was variably perceived. The interactions revealed in (Figure 2), were shown in (Figure 3 ), this indicates that the sensory color properties of commercial weaning flours show greater fluctuation and would not be clearly differentiated by the sensorial panel used.

The differences in this sensory property may have certain implications in products used and incorporated. Also, colour intensity perceived by the panelists was clearly influenced by the brightness of the upper side of the wafer. As well as the color of gruels would be appropriate to dismiss these parameters as discriminating methods to differentiate the flour (Figure 3 ). Based on the results (Figure $2 \& 3$ ), fluidity was close with sweetens of gruel and provide information's about mouth feel, aroma and overall assessment of weaning flours gruels. These results obtained from market weaning flours, may be used as a helpful tool for the evaluation of the sensory properties, quality control and applications in weaning yam-based flours development.

According yam-based formulated weaning flours, relationship between the scores of discriminant scale and the samples hedonic scale could be seen from (Figure 4). The graph in (Figure 4) reveals that yam-based 


\section{Food Science and Nutrition Technology}

formulated weaning flours, sensory properties are gathered into three distinct groups near to the Euclidean distance of 6 .
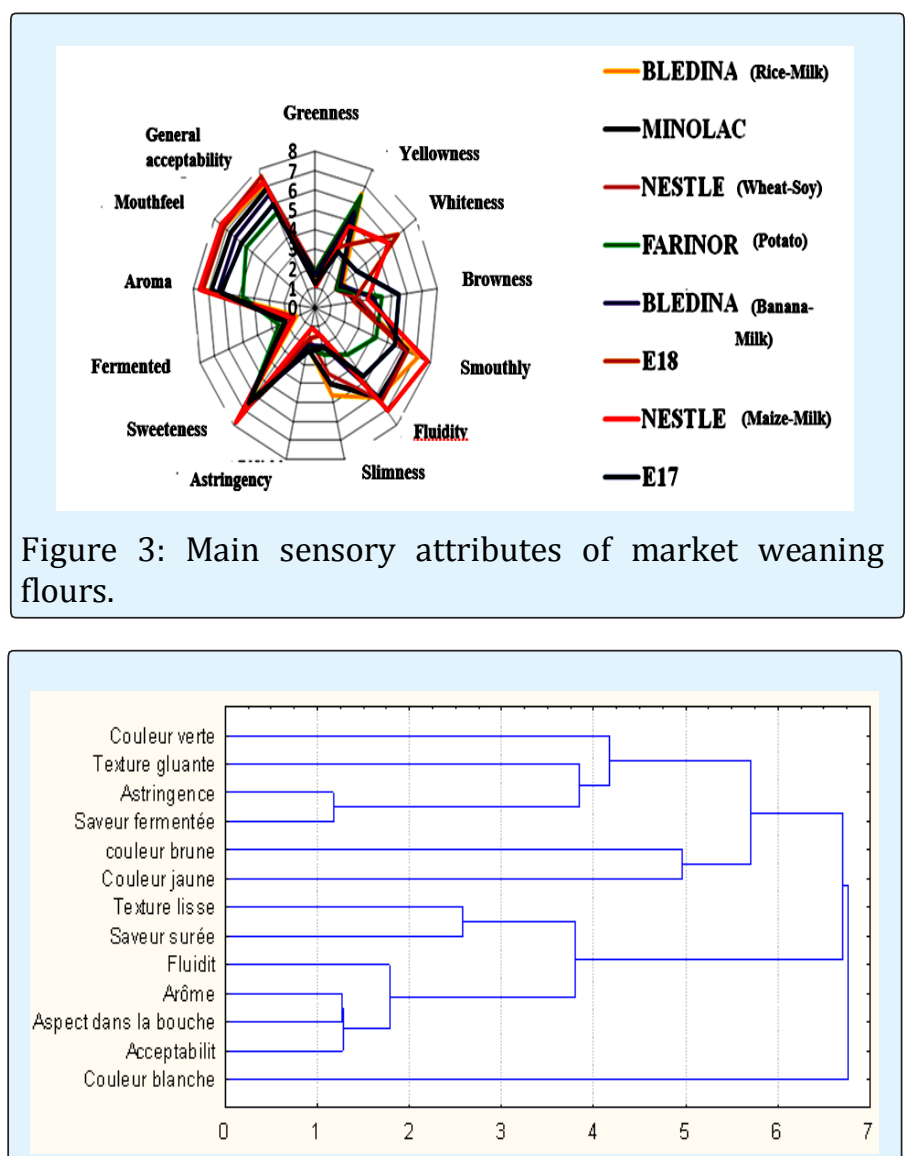

Figure 4: Dendrogram showing the clustering of the sensory properties of the formulated yam-based weaning flours.

One of them (cluster 2) corresponding to which is clearly perceived from all others. It should be noted that Euclidean distance, showed a close association between sensory attributes. In statistical terms, when sensory attributes belong to the same group, they are important for their intensity perceived. However, the overall perception of the panellists does quite corroborate these findings (Figures 5-8). Wide variability observed in the perception from sensory attributes in cluster 1 and cluster 3 are due to the use of different product in the formulation of yam-based weaning flours. Dendrogram obtained with market weaning flours (Figure 2) and yambased formulated flours (Figure 4) are similar with some slightly difference. That indicated a judicious incorporation of studies from market weaning flours into strategic to develop a scheme for processing each material incorporated in composites yam-based weaning flours.
An understanding of the chemical properties that determine each of the sensory attributes of yam-based weaning flours were presented in table 1 . In these analyses, those parameters which did not allow to discriminate were excluded. The positive contribution was mainly attributed to positive coefficient of the parameters, while the negative contribution was mainly attributed to the negative coefficient of the parameters. Negative and significant correlations at $p<0.05$ were obtained between WHC, acidity and astringency, with fluidity, sweetness, aroma, and mouth feel and overall acceptability. Whereas the results showed a very strong positive relation between hedonic attributes (aroma, mouth feel and overall acceptability). The relative contribution of the parameters can be ranked as follows; WHC and acidity are the most important physical properties that discriminate sensory acceptance. Hedonic score are satisfactorily correlated with some chemical data. This funding could explain previously works, who reported that heat-treatment, fermentation and germination are simple household-level food processing, used to improve nutritional and sensory assessment of traditional complementary foods [5]. Used of germinated soybeen and malt millet was to activate alpha and beta amylose act on starch granule and breakdown amylose chains which would typically form gel network. Furthermore, fermentation is used to improve germinated activation, and then improve nutritional quality (flavor, aroma and safety) of composites yam-based weaning food [4]. These processes due to reduce the water-holding capacity and account for the low gel properties of composites yam-based weaning flours porridges. This would facilitate easier consumption, digestion, greater nutrient and energy intake. Also, resolved the inherent problem of dietary bulk associated with yam or hight starch crops, used as complementary foods [16].

In these studies, according results in (Figures 5-8) factors that have affected texture (smoothly and fluidity) includes yams species, germination of soybean, and addition of malted millet. Aroma and texture are affected by fermentation. Reference sample E18, had the best mouth feel and overall acceptability, and followed by sample BbSGM and BbSGMCS. There are no significant difference $(\mathrm{P}<0,05)$ in the mouth feel and overall acceptability, rating of the reference E17 and samples BbSG, BbSGMNB, BbSNGM. Other formulated samples received lower mouth feel and overall acceptability than E17. The differences in the mouth feel rating could be as result of the constitutional variation between yam sample species (Bete Bete and Kponan), germination of soybean and added of malted millet. Mouth feel would determine the amounts of food an infant would consume, because infant commonly swallow as smooth gruel and not a 


\section{Food Science and Nutrition Technology}

coarse product. However, mouth feel rating of the composite blend was within acceptable limit.

Gruel meals flow is important parameter linked with consistency of flour. A very thick consistency would need increased effort to swallow and therefore may limit the food intake in young children who have not fully developed their ability in these aspects [16]. Perhaps, the possibility of adding sweetening and flavoring agent to the formulated food samples should be employed as way of improving the sensory quality of the formulated diets. Color of gruels, hence not be objectionable to the infants, could be further improved by adjusting processing conditions.

Sensory qualities shown in (Figures 5-8) indicated that flavour, taste and texture were improve with greater proportion of sprouted soybean over unsprouted soybean. And then these sensory attributes were improved with greater proportion of malted millet incorporated. All gruels based on Bete Bete yam were rated above average in

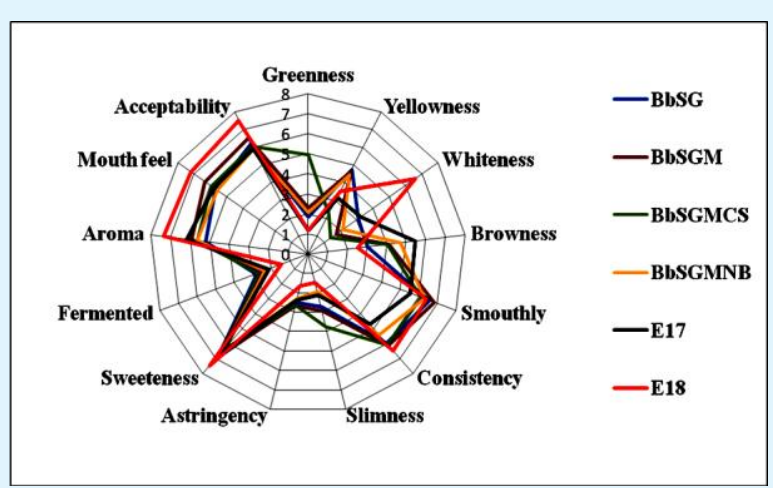

Figure 5: sensory profil of Bete Bete yam / sprouted soybean

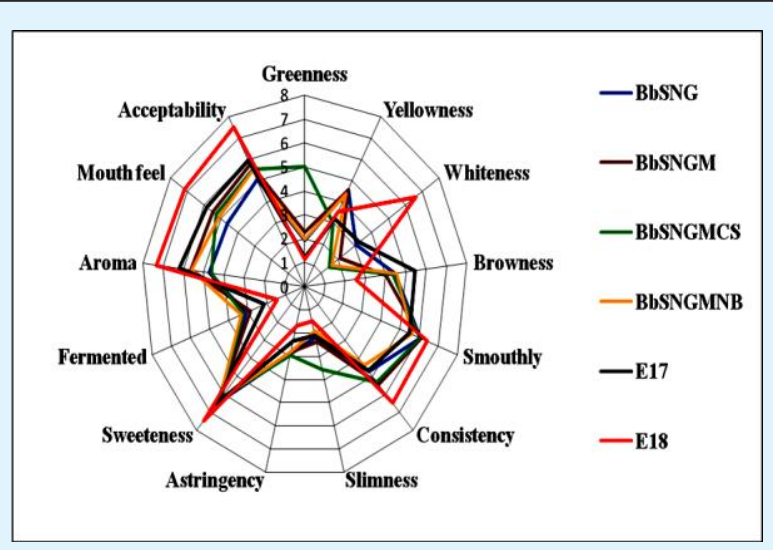

Figure 6: sensory profil of bete Bete yam / unsprouted soybean
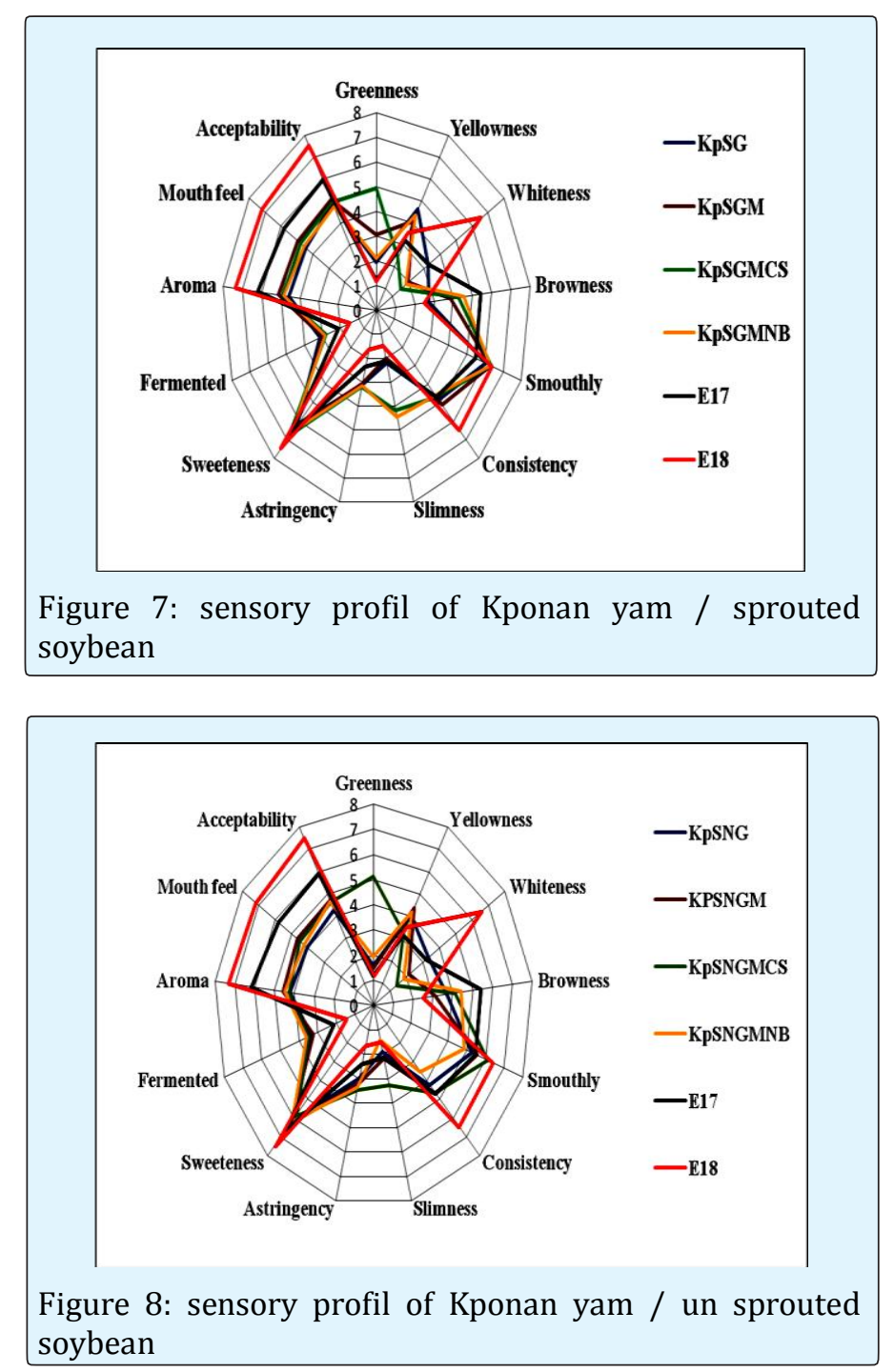

All rows and columns with no strong correlation relationships $(>0.70)$ have been removed from this table. Correlation coefficients with strong interaction were redcolored. Water-holding capacity (WHC): g water/g dry sample, terms of mouth feel and overall acceptability. BbSGM gruel was the most preferred. Malting reduces viscosity of the foods and hence a child can eat more at a time. However germination has been reported to reduce the concentration of ant nutritional factors like phytates in malted grains hence improves its nutritional quality [17].

According composites formulated yam-based weaning flours, sensory quality of BbSG, BbSGM, BbSGMCS and BbSGMNB, compare to the references used complementary foods was liked moderately on the hedonic scale (Figure 5-8). A number of organoleptic features, such as flavour, aroma, appearance and texture, 


\section{Food Science and Nutrition Technology}

may affect infant's intake of transitional foods which may results in increased consumption [18]. Feeding infants with improved complementary foods as that formulated in this study for children may cause improvement in their growth [16].

\section{Conclusion}

Bioprocess used cause considerable changes that will affect the organoleptic properties (taste and viscosity), with good acceptability comparable to that commonly used. There is a great potential for utilizing formulated BbSGM as weaning food. In addition, after optimize their sweet; BbSGMCS and BbSGMNB could have greater potential for utilizing as weanning food with good source of protein and nutraceutical content.

This study suggests that the development of efficient processing technique is warranted for better utilization of soybean, complex of Nere-baobab pulp, C. sesamoides leaves, as well as, to make use of their by-products is values added foods. C, sesamoides and Nere-baobab pulp complex has natural minerals and vitamins sources. Their incorporation into weaning food could improve food qualities.

It can be concluded that, the bioprocess used for manufacturing these complementary food was appropriate and had great preservation of sensory acceptance. However, further studies are necessary to confirm the beneficial effects of those functional substances.

\section{References}

3. Omonigho SE, Ikenebomeh MJ (2000) Effect of temperature treatment on the chemical composition of pounded white yam during storage. Food chemistry 71: 215-220.

4. Sanni AI, Asiedu M, Ayernor GS (2001) Influence of processing conditions on the nutritive value of Ogibaba, Nigerian fermented sorghum gruel. Plant Foods Hum. Nutr 56(3): 217-223.

5. Soro S, Konan G, Elleingand E, N'guessan D, Koffi E (2013) Formulation d'aliments infantiles à base de farined'igname enrichies au soja. african journal of food sciences, alimentation, nutrition and development 13(5): 8313-8339.

6. Solomon M (2005) Nutritive value of three potential complementary foods based on cereals and legumes.
African Journal of Food, Agriculture, Nutrition and Development 5(2): 238-248.

7. Akissoe N, Hounhouigan J, Mestres C, Nago M (2003) How blanching and drying affect the colour and functional characteristics of yam (Dioscorea cayensisrotundata) flours. Foods chemistr 82: 257-264.

8. AOAC (1990) The Official Methods of Analysis of the Association of Official Analytical Chemists (15th ed.). Arlington, Virginia: The Association of Official Analytical Chemists.

9. Corke H, Li J (1999) Pysicochemical properties of normal and low-amylose job's Tears (Coix lachrymajobi L.). Starch Cereal Chemistry 76(3): 413-416.

10. Rodriguez-Ambriz SL, Islas-Hernandez JJ, AgamaAcevedo E, Tovar J, Bello-Perez LA (2008) Characterization of a fiber-rich powder prepared by liquefaction of unripe banana flour. Food Chemistry 107: 1515-1521.

11. Meilgaard M, Civille GV, Carr BT (1999) Sensory Evaluation Techniques, CRC Press, United States of America.

12. Castañeda R C, Cañameras G, Aranibar H (2007) La textura del Queso Goya. Com?paración entre el método sensorial y métodos re $\neg$ ológicos. http://www4.inti.gov.ar/GD/5jornadas/doc/178.doc (Accessed: December, 2007).

13. AFNOR (2000) Analyse sensorielle-MéthodologieDirective générale pour la realisatio d'épreuve hedonique enlaboratoire d'analyse sensorielle ou en salle en condition controlée impliquant des consommateurs. (XP V09-500).

14. Pereira D (2013) Estudo comparativo de bolacha maria de diferentes marcas. Master Dissertation, Instituto Politecnico de Viseu, Viseu, Portugal.

15. Richard A J, Dean WW (2002) Applied Multivariate statistical analysis. Prentice-Hall, London.

16. Alvin C R (2002) Methods of Multivariate Analysis. John Wiley and Sons. INC USA.

17. Pérez C (2004) Técnicas de Análisis Multivariante de Datos. Aplicaciones con SPSS Pearson Prenotice-Hall. España pp: 646.

18. Nnam MM (2001) Chemical, sensory and rheological properties of porridges from processed sorghum (Sorghum bicolor), bambara groundnut (Vigna 


\section{Food Science and Nutrition Technology}

substerranea L. Verdc) and sweet potato (Ipomoea batatas) flours. Plant Foods for Human Nutrition 56 (3): 251-264.

19. Traoré T, Vieu MC, Traoré AS, Trèche S (2005) Effects of the duration of the habituation period on energy intake from low and high energy density gruels by Burkinabe' infants living in free conditions. Appetite 45: 279-286.
20. Aletor O, Owoeye FB, Aletor VA (2009) Effect of fermentation on the physico-chemical composition and multienzyme in vitro protein digestibility of African locust bean (Parkia boglobosa) and soya bean (Glycine max) seeds. Journal of Chemistry and Society of Nigeria (CSN) 34(2): 126-133. 